\title{
Praxiology meets Planning Theory of Intention. Kotarbiński and Bratman on Plans ${ }^{1}$
}

\author{
Piotr Makowski \\ Adam Mickiewicz University in Poznan, \\ Poland
}

\begin{abstract}
Planning organizes our actions and conditions our effectiveness. To understand this philosophical hint better, the author investigates and juxtaposes two important accounts in action theory. He discusses the concept of a plan proposed by Tadeusz Kotarbiński in his praxiology (theory of efficient action), and the so called "planning theory of intention" by Michael E. Bratman. The conceptual meeting of these two proposals helps to remove flaws in Kotarbiński's action theory, it also shows the way, in which we can enrich the idea of plans in the framework of intentions. Generally, praxiology occurs to be still an important perspective in action theory, which particularly shows how we can improve our understanding of planning when confronted with influential contemporary accounts.
\end{abstract}

\section{Introduction}

Planning is a large part of our temporally extended agency. It organizes most of our actions which need to be prepared before execution. As Michael Bratman used to say, we are planning agents [e.g. Bratman 2007: 3]. Naturally, this is not the whole story about our agency. We not only plan our actions - we get things done. So we are - and should be - effective creatures. For a practical being, there is almost pressure towards finalization, as H. J. Krämer put it ${ }^{2}$. Planning makes sense, because of its long-lasting effects on action. Indeed effectiveness would not 
be possible - at least in many diachronic dimensions of human practice - without planning. My aim in this paper is to try to elucidate a little on this philosophical hint. To achieve this, I shall focus on the intersection between two approaches to planning: the one proposed in the so called planning theory of intention (henceforth $P T I$ ) by Bratman, and the one called praxiology (proposed by Kotarbiński) which is focused on human effectiveness. As we will see, both these two tactics work in the same business and - after a few critical modifications - may mutually support one another. Unhappily, these two approaches do not permit a comparison that would show this mutual cooperation easily. Before the attempt at bringing these accounts together, one needs to hermeneutically prepare both of them. I shall in particular focus on praxiology, since there are at least two reasons which make the task of interpreting it a demanding one: firstly, praxiology, especially in the sense in which I (after Kotarbiński) use this term, is not a widely known field of study. Secondly, there are internal theoretical peculiarities and difficulties (partially responsible for the fact that a wider international reception of praxiology had been impeded), which make it hard to accept. Thus, the aim of this paper can be also understood as a preparation of praxiology for its meeting with the planning theory of intention (but, as we shall see, such preparation can also take the opposite direction). PTI has been widely discussed from many different aspects in the literature on action theory, while the same cannot be said about praxiology. Nevertheless, the possible theoretical outcome of their meeting promises something that seems to be neither noticed in the literature on the Bratmanian "planning theory", nor-I dare to say - in international debates on action theory taken en bloc.

The structure of this work is as follows. Firstly, I briefly explain how I understand praxiology and why it is still an important perspective in action theory. Here I present the core of the programme which was first proposed by Tadeusz Kotarbiński under the heading "praxiology". Secondly, I present Kotarbiński's understanding of plans. Here I point out, inter alia, the difficulties of his philosophical elaboration of the concept of a plan, which make it obsolete, at least, in its overall theoretical framework. Thirdly, to put the praxiological discussion about plans on a more current and philosophically feasible track I briefly characterize the Bratmanian approach to plans as seen from the perspective of his theory of intentions. I present it as the most promising framework for praxiology (at least, for the concept of a plan, the account of which is an important part of praxiology). Since this characteristic initially reveals 
its praxiological dimension, I try, in the fourth step, to explain in more detail why the Bratmanian approach to plans can be interpreted as a praxiological one. The fifth section is a critical discussion of Kotarbińskian views on plans in the light of the results gained from my deliberations in the previous parts of the essay.

\section{2. "What the hell is praxiology?"}

Despite the implications of the above heading ${ }^{3}$, praxiology still seems to be important. It has quite a long tradition commonly associated with Ludwig von Mises (spelled in his writings as "praxeology"), but undoubtedly, there are other interesting, non-Misesian proposals. At least two other roots of praxiology are noted - French and Polish (see Alexandre \& Gasparski 1999). I shall not investigate the historical differences and similarities between them. The provenance of praxiology, as I understand it, is the Polish tradition established by the Polish philosopher Tadeusz Kotarbinski (Warsaw-Lvov School). In my opinion, Kotarbiński's praxiological work, developed in the 1950 s, is not only much more analytically elaborated and nuanced than the French and Austrian accounts, but is - so far - the one and only truly philosophical example of praxiological thinking. Praxiology, in the sense which I accept, is a field of philosophical theorizing which: (1) has been consistently developed from the angle of human effectiveness and efficiency in action; (2) tries to describe the most basic and general conditions for such effectiveness and efficiency. Three definitions are in order here:

1. Effectiveness: an action is effective when it leads to or helps lead to the result taken as its intended goal.

2. Efficiency: an action is efficient when it is effective and it is the most economic of the effective options available.

3. Economy: an action is the more economic the fewer mental and physical resources it requires to reach its goal ${ }^{4}$.

Naturally, not all actions are interpretable in terms of efficiency and economy. Some of them may fulfil the condition of efficiency, but others may not. So praxiology should be a heterogenic discipline which is trying sensibly to account for the empirical context of actions. It can be described as an action theory that aims to show general normative conditions of effectiveness and efficiency in action. Its aim is to show the way we 
optimize our actions when meeting these conditions; so, when given these conditions, we may also predict whether we will succeed or fail $1^{5}$. So construed, praxiology is not anything new - many action theorists are implicit praxiologists: action theories are volens nolens about our effectiveness and its conditions ${ }^{6}$. Nevertheless, praxiology is still an open project, precisely because the implicit approach to these conditions seems dominant. The talk of effectiveness and efficiency is rampant in contemporary practical sciences, to the extent that it is philosophically overwhelming, so it seems that praxiology should also be highly interesting and important for those who work outside the field of philosophy of action. It may offer wideranging conclusions that may be useful for moral thinkers, legal theorists, economists, game and decision theorists, or cognitive psychologists, among others. Before I say something critical about it (in a positive or negative sense), a brief presentation of what it is, is in order.

Praxiology, to satisfactorily explain the normative conditions of human effectiveness and efficiency, has to give an account of both simple individual actions and of shared/cooperative agency; it has to explore both descriptive concepts referring to action (in praxiological ontology, where elementary concepts are explained: action, event, individual and shared agency, agent, goal, result, etc.), and typically evaluative language of action (praxiological value theory, including inter alia effectiveness, economy, skill, etc.). These accounts are to be consequently formulated from the angle of theoretical knowledge which could improve the sphere of praxis via an account of praxiological norms (preparation, agglomeration of goals, automation, among others) ${ }^{7}$. Kotarbinski called these competences of praxiology "the grammar of action". In what follows, I discuss the original structure of his praxiology in more detail (Makowski, unpublished); here I shall focus on selected problems of plans, which in nuce show all the dimensions of praxiology (ontological, evaluative, and normative). As I pointed out at the beginning, the philosophical hint is that planning - which is an organizer of our diachronic agency - is one of the ways in which we make our actions both effective and efficient.

Praxiology aims to give an optimizing account of agency. This, together with the orientation towards effectiveness and efficiency, means that praxiology is interestingly close to the idea that we are resource-bounded agents (proposed by Herbert Simon). This is especially noticeable in the account of planning. But before trying to understand this idea here, we need to know what plans are and how praxiology proves that planning is the way we organize our diachronic actions. 


\section{Kotarbiński on plans (1): a "dottle" of reism in praxiology}

Let us begin with some brief historical and hermeneutical remarks. Kotarbiński paid philosophical attention to plans long before they entered the still vivid debates on action theory and artificial intelligence. His account was developed originally in the mid 50s. and early $60 \mathrm{~s}$. of the $20^{\text {th }}$ century and presented in two papers [English editions: Kotarbiński 1962a, 1983] and in his 1955 opus magnum Treatise on Good Job [edited in English as Praxiology, Kotarbiński 1965]. Kotarbiński was aware that plans were of the first importance in practical thinking. One of his papers started with the statement: "The concept of plans is coloured with the tincture of topicality" [Kotarbiński 1983: 15]. Before clarifying why plans are topical in the sense used by the Polish philosopher, let me shed some light on how he understood them. The word 'plan' is ambiguous, which means it has at least two senses. On the one hand, it characterizes a planner, her state of mind - in the sense of 'having a plan'. It is a psychological concept. Let us call the account which defines plans in this way: Plan Internalism (henceforth - PI). On the other hand, 'plan' can be a linguistic expression [Kotarbiński 19612a: 193] or an external description understood as a complex sign, a perceptible image (Kotarbiński said "an icon") of planning, for example: a set of written sentences. It is an ontological concept. A plan in this sense is not necessarily accompanied by a plan as a mental state. Call it Plan Externalism (PE) [see Kotarbiński 1983: 19-21]. Now, which of these two, $P I$ and $P E$, seems to be more viable in action theory?

To answer this question, we need to allow for Kotarbiński's ontological and semantic views. The Polish praxiologist was a proponent of the so called "reism" (or concretism) in ontology; the semantic version of it consists of the distinction between genuine names and the so called "onomatoids" (apparent names). A name is genuine if and only if it refers to concrete spatio-temporal objects. No concrete object is a property, relation, or state of affairs. The latter are onomatoids names which only allegedly refer to abstract entities: onomatoid is a name the referent of which does not exist ${ }^{8}$. It now becomes clear that plans according to $P I$ do not exist (in the reistic sense), "plans" are only apparent names or vicarious phrases. Despite the fact that plans as mental states are in common use in our practical language, they seem to be insignificant for ontological reasons: 
[W] henever somebody plans [something] we may correctly maintain that he makes a plan, devises a plan, considers a plan of his actions; however, it should be borne in mind that the function of the term plan, in this sense, is that of an onomatoid, hence it does not involve any commitment concerning the existence of any object called a plan. [Kotarbiński 1983: 22]

It is more than obvious that reism in action theory proposes a consequent $P E$ : we should rather neglect our consideration of options, our mental aspects of intending and decision-making (a large dimension of agency) and put stress on their tangible results and effects in external world. Now, does $P E$ save the reistic definition of plan in terms of genuine names? According to $P E$, plans exist only if an agent wants to communicate the action intentions - plans need to be created as external concreta, made available to other agents. Consider the definition of plans:

[A] plan is an icon of something intended which represents either temporal stages of its object, or the spatial structure of its contemporary parts, or the structure of its causally related constituents. Needless to say, components of the above alternative do not exclude one another and it is possible that a certain plan includes two or three of them jointly. Icons of the first kind are called temporal plans; for example, the programme of a concert belongs to them. [Kotarbiński 1983: 22-23]

We see that such a definition embraces not only plans as mental attitudes of intending in the form of sentences externalized "on paper", but also things like recipes (of preparing a soup, for example) or schedules (like railway schedule), or architectural plans. So it is an extremely broad definition and extends beyond the standard spectrum of interests of action theory ${ }^{9}$. But, this problem aside, the $P E$-definition - though advisable by reism - bears with it problems in terms of reism itself. Take an architectural plan of a structure to be built. It is also an example of a plan in Kotarbiński's terms. If the building is something intended to be constructed in the future, its plan is still "an image" of something nonexistent, or - an image of nothing. The definition of a plan is no longer reistic, but it has become nonfactualist ${ }^{10}$. Kotarbiński tried to solve this problem claiming that to say that a plan is an image of something intended is to say that "a plan shows what something intended will be like if our intentions are satisfied" [Kotarbiński 1983: 25, my italics]. This vulpine interpretive manoeuvre, stressing the praxiological importance of effectiveness (the talk of "satisfied" intentions), seems to secure reism, but actually, it only highlights the problem which is inherent in action 
theory (at least in the sphere of our investigations): the inescapability of psychological concepts and intentional language as such. This definition shows that it is extremely difficult to talk about any effects of the mental aspects of planning without intentions. So, reism is a dead end in action theory, because it obfuscates the role of our agential psychology. That is why Kotarbińskian practical philosophy is highly problematic if not totally flawed ${ }^{11}$. Nevertheless, I am prone to say that the interpretation of the reistic definition of a plan offered by Kotarbiński is awry in the sense that it can be seen as an argument for PI. Plans as mental states causally and logically precede plans understood as external descriptions, so intentions and intending seem to be irreducible. That is why one may say: a plan shows what that which is intended will be like if it ends up being as we intended it to be ${ }^{12}$. In other places, Kotarbiński himself stressed that the analysis of plans understood as linguistic expressions remained in touch with the idea that planning was a psychological issue, and we were the planning agents [Kotarbiński 1961: 193]. Therefore, the point of the story about reism in action theory may be this: we can safely narrow down the concept of a plan to one of mental attitude, and redefine it in terms of intentions, or in other words - replace the reistic ontology with the framework of the philosophy of psychology.

\section{To merge praxiology with $P T I$ : plans as complex future-directed intentions ${ }^{13}$}

We are looking for another conceptual framework for plans which would be compatible with $P I$. But, by suggesting this I do not mean to say that $P E$ is flat-out wrong. There are fields of science where the external approach to plans is useful (e.g. abstract structures projected in $A I$ [Bratman 1987: 29]. Nevertheless, in action theory where we consider the diachronic dimension of agency, PI seems to be much more feasible. If this is the case, $P I$ should also be promising for the praxiological understanding of actions. Let us recall that planning, as a special case of mental activity, organizes our diachronic agency and is one of the ways in which we make our actions effective.

I stipulate that PTI which has been proposed by Michael E. Bratman offers the most attractive framework for a praxiological approach to planning. The whole idea of PTI is to use common-sense talk of plans to elucidate a specific type of intentions: future-directed ones. In turn, such a manoeuvre improves our common-sense understanding of plans 
and shows their basic structure. So, PTI narrows down the scope of understanding plans to mental attitudes (or pro-attitudes if you like), which support - both intrapersonally, and interpersonally - the organization of our future actions [Bratman 1987: 18; 1992b: 2]. When, for example, I intend in January to go to California in April, I do not only express my desire to do so. I specifically commit myself to that and not another course of action. Such a commitment is, of course, revocable, depending on the changes in my present agential environment or simply - on a change in what I want. What about plans?

My future-directed intention to fly to California in April cannot be instantly fulfilled. Such an intention diachronically structures at least a few actions: I need to include the trip into my work schedule, buy tickets, book hotel and so on. These actions have to be, at least in part, properly sequenced. This is how we make our plans. So, plans are similar to future-directed intentions, but are much more complex, because they embed other intentions.

Although Bratman occasionally identifies plans with future-directed intentions, I accept his official stance: intentions are "building blocks of plans" [Bratman 1987: 8]. or, they are "plan states" [Bratman 2010: 9]. Plans are partial chains of intentions ${ }^{14}$. (This understanding of plans can be supported by Kotarbińskian talk about plans as sets of sentences [Kotarbiński 1961: 191]). Let us characterize them in more detail. Firstly, plans control our actions, because of their specific stability - the feature which they inherit from the stability of future-directed intentions ${ }^{15}$. If I intend now to go to California in April, the issue of going there is settled as a "default" option until the time of action. "If my future-directed intention manages to survive until the time of action, and I see that time has arrived and nothing interferes, it will control my action then." [Bratman 1987: 16]. This stability is not total: "given new information, or a change in what I want, I may well reopen the question and reconsider" [Bratman 1987: 16]. Secondly, plans serve as an input for further reasoning about other intentions. The intention to go to California runs other intentions: to buy tickets, take care of accommodation, meet my friend there, and so on. Thirdly, plans are hierarchically structured. My intention to go to California constitutes a goal, it embeds relevant means, which can be understood as specific, sometimes interlocking, sub-plans. Fourthly, plans are also essentially partial: in January, when forming my plan to visit California in April, I do not have to care about all the sub-plans it requires to be filled out - say, the destination (San Francisco or LA) 
or the booking of a hotel (in the Hilton or Sheraton) - such intentions can be formed later and gradually over time. Improving the details of a plan supports its effectiveness, but it is not a necessary condition of plan effectiveness [Bratman 1987: 179, n. 5] People may also make general "life plans" (in the sense of life strategies) which essentially cannot be planned all at once [Bratman 1987: 29-30]) ${ }^{16}$.

So, according to PTI, plans should be consequently understood as similar to future-directed intentions ("plans are intentions writ large" [Bratman 1987: 8] but different from them due to their complexity. To sum up: plans are complex chains of future-directed intentions, which: (1) are conduct-controllers (because of their stability), (2) are relatively stable, (3) serve as a further-reasoning-input, and (4) are hierarchically structured. No surprise, this characteristic ex definitione implies PI: $P T I$ is an account of plans considered as a psychological issue. Thus, if a praxiological approach to plans is feasible, it should be feasible in terms of PTI (or something close to it). I have hinted that plans support our effectiveness in diachronic agency. I have also said (sect. 2), that proper praxiology involves an investigation of the normative conditions of effectiveness. I claim that PTI offers an account of such conditions we will browse through them in the next section. In this way, it should become clear that praxiology can be - at least prima facie - merged with PTI, because Bratmanian action theory has a deeper praxiological dimension. To see this dimension, we need have a closer look at standards that plans should meet in our rational diachronic agency.

\section{Bratman on plans: the minimal praxiology}

Plans have to meet at least some of the regularities of our mental processes within which the building blocks of plans are moored. This is a heritage of functionalism in philosophy of mind in $P T I^{17}$. Without going into details, it is enough to notice that these regularities can be understood as norms for future-directed intention ${ }^{18}$. Due to some difficulties [see e.g Kolodny 2008], a comprehensive discussion of these norms would require a very detailed study, here I shall focus just on their "face value".

According to Bratman, there are four types of norms of plans: internal and external consistency, means-end coherence, agglomeration and stability ${ }^{19}$. Let us begin with consistency. Intentions should be consistent internally, i.e. they should not contradict each other. Turn back to my plan to visit California and the way I fill in this plan with details: my 
intention to visit San Francisco cannot be accompanied by my intention to meet friends in Warsaw at the same time - my plan would be then executed ineffectively (to say the least). Plans should also be consistent externally: they should be in accordance with my beliefs. I cannot intend to go to California in April if I believe that in April I will be in Krakow at my cousin's wedding (because I have already accepted an invitation to attend it).

Planning means action organization. Besides being consistent, plans should be coherent with respect to the relation between the means and plan end. This demand on plans is related to their partial character and hierarchical structure. Effective plans embed relevant means: my plan to go to California would not be successful if I decided to go there by train (given the belief that I shall still be in Europe before I go). Nevertheless, the means I engage to reach my goal do not have to be set "down to the last physical detail" [Bratman 1987: 31]. The norm of means-end coherence should be sufficient to execute a plan, it does not force plan detail.

The norm of stability, the third in this presentation, is probably the most problematic in Bratman's works. We have seen that stability is one of the descriptive features of plans and intentions. Here it is to serve as a norm. What is the difference? Its core seems to be anchored in the idea of reasonable stability. In contrast to intention stability understood as a default practical option after decision-making (called by early Bratman also "intertia") ${ }^{20}$, stability as a norm should be reasonable [Bratman 1987: 72]. It can be defined as the result of an assessment of the agent's attitude over time, in a particular case. To elucidate this norm, Bratman engages the so called "two-tier approach to non-reflective (non)reconsideration" [Bratman 1987: 64-71, see also Holton 2004: 510], which is a model of rationality of an agent. The first tier is responsible for the pragmatic disposition not to reconsider prior intentions, i.e. it relies on the intention stability described as a "default" - the feature which intentions inherit from the more general psychological tendencies not to reconsider prior decisions. At the second tier, we assess particular situations from the angle of the reasonableness of this "defaultness": "We may then say that nonreflective (non)reconsideration of a prior intention was rational of $S$ if it was the manifestation of general habits of reconsideration that were reasonable of $S$ to have". [Bratman 1987: 65]. So, the norm of stability is more complex than consistency and coherence. Its particular shape depends on context and circumstances. We should also bear in mind that, given the Bratmanian occasional identification of intentions with plans, 
the norm of stability applies uniformly to plans with no modifications [see. Bratman 1987: 65]: plans should be as stable as future-directed intentions should be.

Notice also that despite its overall importance for the effectiveness of diachronic agency, stability as described by Bratman does not have a universal application. Bratman deliberately narrows his account down to the situations-in which we either retain or reconsider prior intentions ${ }^{21}$. But it seems that there are many cases where these two do not exhaust the problem of agential stability - all of them rely on abandoning intentions without reconsideration. What about my overall psychological stability, if I have to abandon my plan to visit California, simply because, say, the airlines are on strike? Unfortunately, Bratman does not say much about such cases of stability and leaves this aspect of our planning untouched. It even seems that the picture of psychological stability ("two-tier model") should embrace such cases on a par with the standard situations of intention retention and reconsideration ${ }^{22}$. This line of thinking appears justified in the light of further theoretical support which Bratman gives to stability. He refers to three ideas: (1) "the snow-ball effect" of intentions: acting on prior intentions changes the world in a way that escalates the agent's sensibility of continuing to act on the basis of that intention, (2) the costs of reconsideration by resource-limited agents: there are reasons not to reconsider prior intentions, because it takes time, requires mental costs and resources. This support can be interpreted as an extension of the idea of resource-boundedness. Finally, (3) general propensities favouring non-reconsideration: our psychological dispositions to retain prior intentions support our effectiveness [Bratman: 2010: 12-13]. Stability, according to Bratman, is not only a crucial norm of planning, but it traces something very primal in the psychology of action - although Bratman's elaboration of this seems to leave something to be desired.

Plans consolidate our temporally extended actions in various ways. The last norm of planning, detected by Bratman, is the agglomeration of intentions. If in one and the same time an agent intends $A$ and intends $B$, then it should be possible for him/her to intend both $A$ and $B$ : "[t]here is rational pressure for an agent to put his various intentions together into a larger intention" [Bratman: 1987: 134]. If I intend to visit San Francisco in April to go there for a jazz concert and I intend to meet my friend in San Francisco, it is rational to have these intentions together. Such an agglomeration is a part of the normative net of our agential psychology: it comes with the constraint of internal and external consistency. In the 
case discussed, my intention to visit San Francisco and the intention to meet my friend are mutually consistent, and are consistent with my beliefs (say, I believe that my friend will be in SF in April, and our schedules are compatible). Intention agglomeration supports my overall effectiveness in a distinct manner.

Let us take stock. We have four mutually supporting norms of plans. The praxiological dimension of the Bratmanian approach to them is rather clear. The norms of planning are all implicitly oriented on the effectiveness of diachronic agency, and I pointed to this fact when presenting each of these norms. A praxiologist would say that these norms are explicitly necessary conditions of effective diachronically organized actions. But immediately, the new praxiological question arises: are these conditions sufficient for their efficiency? What if the praxiology of $P T I$ can be interpreted and enriched in a direction that would make it more optimal?

Consider now the intention agglomeration again. No doubt, Bratman remained minimal in his account of this norm, in the sense that his presentation of it was curt. In fact, some critics have already correctly noticed that Bratman has left this norm of planning without further elaboration and support [Zhu 2010]. Still, if we support it in a suitable way, we shall see that $P T I$ is open to a more optimizing interpretation that clearly distinguishes effectiveness and efficiency. My plan to go to California embeds a few intentions which in some circumstances should be agglomerative. If I intend to visit San Francisco in April to go for a jazz concert and I intend to meet my friend in San Francisco, it is normally reasonable for me to have both these intentions agglomerated. But there are two conditions for this reasonableness. Firstly, these intentions have to "play in the same game" (to put it in a metaphor): they need to be related in a significant manner in the same practical scenario ${ }^{23}$. Secondly, intending both to visit SF to go for a concert there and to meet my friend in SF has to be more economic than the intending of these two separately (in two individual planning scenarios). I would need another plan (engaging new relevant resources) to meet my friend in San Francisco, if my plan to visit California (with the intention to attend a concert in SF) were not already in place. Agglomerating (or clustering) future-directed intentions in one larger "amalgam" or compound intention simplifies and eases our actions. In this way, we economize our planning agency ${ }^{24}$. And this is something more than the standard effectiveness-oriented interpretation of PTI offers, since the conditions of being effective are not always the 
conditions of being efficient. It appears that praxiology helps to understand PTI better.

We have seen that Bratman stayed parsimonious in his presentation of the norm of intention agglomeration, and, at the same time - that the norm itself can be seen as praxiologically distinguished. Still, there is another reason why Bratmanian PTI can be understood as a minimal praxiology. I have said that Bratman occasionally identified plans with future-directed intentions. So, according to his approach to PTI, the norms of plans have to be volens nolens restricted to the norms governing intentions. Naturally, it is possible that the underlying regularities of intentions and plans produce one and the same set of norms for both of them, but Bratman - due to the above mentioned identification - could not have shown this. This paves the way to answer the question I asked two paragraphs earlier: what if plans have to meet other praxiological standards, beyond the scope of standards for intentions? I urge to accept this option rather than the opposite one. To show how this option can be realized, we need to have a closer look at the optimal praxiology of planning which had been projected by Kotarbinski.

\section{Kotarbiński on plans (2): planning from the perspective of $P T I$}

The Kotarbińskian approach to plans, incompetently opting for $P E$ in action theory, is free from the problem of identification of plans and future directed intentions. Prima facie, this gives Kotarbinski a sort of advantage over PTI: despite the fact, that his reistic conception of a plan is somewhat flawed, it might still be the case that his view on standards of plans could enrich or correct the account offered by Bratman. Let us check it.

Kotarbinski was perfectly aware that plans are conditions of action preparation [Kotarbiński 1961: 189]: "the planner must somehow mould himself” [Kotarbiński 1965: 117]. Planning pragmatizes agency. The norms of plans constitute a specific subclass of more general praxiological norms. Before I start to discuss the standards of plans in detail, a remark is in order. Kotarbiński, when proposing his account of plans, confused a few things. Even the titles of his works advise some caution. In all three works where he proposed his theory of plans, he very liberally used various terms to characterize them: a property, a feature, a value, a virtue, a postulate, a demand, a requirement, and a norm. It would be difficult, 
without further amplification, to discuss things given such different names under the one heading of norm. Following Bratman's distinction between the descriptive characteristic of a plan and its normative constraints (norms), I shall try to distinguish these two in Kotarbiński.

Despite the mentioned confusion, Kotarbinski, at first glance, seems to have a head start over Bratman. He offers not just four but a whole list of properties and norms of plans: purposefulness, feasibility ("workability"), internal consistency, rationality ("cognitive justification"), operativeness, plasticity ("flexibility"), (limited) detail, (limited) long-term, terminus ad quem, completeness, economy, and finally communicativeness (in cooperation) [Kotarbinski 1983: passim] ${ }^{25}$. From the perspective of optimizing ambitions of praxiology, that list may look more promisingthan the modest set of four norms offered by Bratman. However, it may look suspicious as well. In what follows, I shall try to present all of these "norms", critically embedding them in the context of PTI. Therefore, the task is to find in this Kotarbińskian jungle of concepts at least some grounds to extend minimal praxiology towards an optimal one.

Let us begin with the quote about purposefulness and feasibility:

"The most important feature of a good plan is its purposefulness; namely, it
should indicate proper means to achieve a desired aim. Secondly, a good plan
must be workable; (...). Before we perform a projected action we should have
a good plan and know its value; however, the only way to make sure that an
intended action is workable is to perform it. Hence unquestionable knowledge
concerning the possibility of performing a certain plan can be achieved ex post,
that is, at the moment when the plan itself becomes useless. There is no way out
of it." [Kotarbinski 1983: 25]

Kotarbiński's purposefulness is nothing other than Bratman's meansend coherence. In both cases, the idea is that the means engaged should be suitable for the plan's end. If one accepts its normative character, it should not pose further difficulties. Feasibility (or somewhat clumsy "workability") appears more problematic. On the one hand, it seems to be a supplement of means-end coherence, because it may serve as an external post factum test of it. Its normative character does not seem problematic either: if an agent disregarded the feasibility of her plan, she could not expect a success of that plan. On the other hand, if we reinterpret it in terms of the conditions ex ante, as the thinking of normativity suggests, that norm seems to be the resultant of what Bratman calls internal and external consistency and means-end coherence (purposefulness). Why? If a plan is both means-end coherent and internally and externally con- 
sistent, it should be a feasible plan. At least, if an agent $S$ plans - given these three conditions - to do $A$, it is reasonable of $S$ to expect that her plan will be feasible. So, if Kotarbinski offers something close to internal and external consistency, this norm seems to be redundant. And that, I think, is the case.

Let us consider the norm which he calls (again, a bit awkwardly) rationality:

\begin{abstract}
"We would maintain (...), that a plan should be reasonable (...). The rationality of a plan, according to our understanding of the word, depends on the cognitive justification of its components, therefore on the cognitive justification of a plan as a whole. The difference between realistic programmes and utopian vagaries lies in that the former are based on the knowledge of facts and their relationships, which precludes adventurous recklessness. It seems there is no need to stress that a plan can be more or less rational in this sense of the word (...). That is why we do not simply say that a good plan as such should be rational, but we maintain that the more rational a plan is, the better-ceteris paribus - it is." [Kotarbiński 1983: 28]
\end{abstract}

Rationality, or cognitive justification, says even more than the norm of external consistency. It at one go stresses that plans should be consistent with our relevant beliefs, that such consistency should be optimally increased, that the beliefs (with which our plans are consistent) should be true and also that these beliefs should be optimally justified. So, the main idea seems to be fundamentally in accordance with Bratman's account, but it is explicitly formulated in an optimizing direction. Even Bratman would probably say that external consistency between a plan and a few random beliefs is worse than external consistency between a plan and the whole set of justified relevant beliefs. This shows that the understanding of external consistency in a more optimizing sense is viable.

Next, let us have a look at the norm which Kotarbinski calls.. internal consistency ${ }^{26}$ :

When a plan is (...) internally inconsistent, it becomes totally unworkable. There is thus no controversy over whether a plan has to be consistent, or not; whether it can contain a project of doing something definite and, at the same time, of not doing it. [Kotarbiński 1983: 25].

Although imprecise, this can serve as a definition compatible with the one offered in PTI: a plan is internally consistent if the intentions which build a plan do not contradict each other. This seems correct. Kotarbinski immediately tries to suggest something that looks like an optimizing 
extension of this norm. Still, this time, such an extension is not convincing. According to his understanding, there are two "better" versions of internal consistency: harmony of a plan, where the subplans are not only consistent but also harmonically support themselves; and organicity, where internal consistency reaches its maximum in the plan structure [Kotarbiński 1983: 26]. I find both these manoeuvres implausible, despite the fact that generally speaking optimal praxiology of plans is a valuable option in action theory. The reason why this strategy is implausible is that only some plans should be in fact harmonic or organic. In most cases, optimal plans should be just (ceteris paribus) internally consistent. I do not see any convincing argument for my plan to visit California in April to be organic. Also, it does not become more effective or efficient when I combine its steps harmoniously. These seem to be only the aesthetic values of my plan, normatively irrelevant for its success ${ }^{27}$.

Now, we can turn back and solve the problem of feasibility. Given the fact that rationality, understood as the plan's external consistency, in combination with its internal consistency offers the necessary and satisfying condition to perform - with rational expectance of success - the planned action, I suggest this "norm" be taken as one of the examples of Kotarbińskian superfluous scrupulosity.

Let us now consider the "postulate" which seems to be close to the norms of internal consistency and means-end coherence. In the Treatise it is called consequence (or continuity) ${ }^{28}$. Kotarbiński understood it as a diachronic consequence between the means and end in the sense that some prior steps prepare future steps [Kotarbiński 1965: 119]. If we take this "postulate" as a norm, it happens to be redundant with respect to means-end coherence. The latter implies that some steps prepare other steps; otherwise they would not be their means. To find a way out of this difficulty, we should interpret it in a different manner. The idea that helps comes again from Bratman. Among the crucial descriptive features of a plan, the American philosopher points out that typically it is hierarchically structured. As we recall, this means that plans "concerning ends embed plans concerning means and preliminary steps" [Bratman 1987: 29]. These two issues are not identical, nonetheless, they refer to the same phenomenon: plans are hierarchically structured in the sense that they imply the consequence between means and ends: "As a result I may deliberate about parts of my plan, while holding other parts fixed. I may hold fixed certain intended ends, while deliberating about means and preliminary steps" (Ibid.). Therefore, my solution to the problem 
of (diachronic) consequence is a refutation of the idea that it is a norm, and enlisting it into the descriptive features of a plan (as a variant of its hierarchical structure).

A similar problem appears when we discuss the question of plan detail. Kotarbiński also seemed to hesitate as to how this feature should be described. On the one hand, he proposed that a plan should be detailed, albeit detailed suitably, i.e. he opted for limited detail. On the other hand,

\begin{abstract}
"(...) in many cases it is more reasonable and economical to have some items undetermined; their determination is left to a future executor who will make them precise when certain important and reliable information becomes available." [Kotarbiński 1983: 27]
\end{abstract}

Bratman would probably say simply that plans are partial. And, after merging the theory of plans in PTI (having removed the reistic "dottle" I discussed in section 3), I do not see any reason to interpret Kotarbiński, in his talk about plan detail, in a different manner than the one offered by Bratman. All the more as the talk about plan limited detail (or its partial character) is for both authors supported by the idea of the mental economy of a planner. Therefore, plan (limited) detail describes a feature of planning; that is its initial fragmentariness.

Kotarbiński noted that the problem of plan detail is analogous to another issue: the long term of a plan:

\footnotetext{
“(...) there are the same reasons which prevent us from determining particular steps of a complex action if its future conditions are not known with sufficient precision, and which prevent us from anticipating too many such steps. If our knowledge of the circumstances is too scarce, both interpolation and extrapolation should be limited. In some cases, therefore, we can formulate plans which reach the distant future, in others, those limited to the nearest future; this depends on how valid and how inclusive our anticipations concerning future conditions of the action are." [Kotarbiński 1983: 27]
}

Having replaced the talk of (limited) detail with talk of the partial character of plans (or their fragmentariness), we can easily get rid of the problem Kotarbiński describes in the above quote. If plans are partial in the sense that their details are underdetermined, it is clear that they are partial in the sense that their duration is underdetermined. Here the Bratmanian idea of the partial character of plans seems to be more useful, because it embraces these two aspects. But there are two points here. On the one hand, Kotarbiński, in his discussion of the detail and duration of a plan, reveals something that makes his approach more precise than Bratman's, since he 
shows two dimensions of a plan's partial character. On the other hand, we should remember that both these aspects of our plan belong rather to its characteristic features, therefore - they are not the norms of our plan.

A different problem appears with the idea of terminus ad quem of a plan, i.e. the idea that a good plan has to be limited: "The terminus ad quem we are speaking about is the moment by which the work has to be done; the limitation date by which a given result has to be achieved." [Kotarbiński 1983: 27]. At first glance, it seems perfectly reasonable to think that our plans should always have a deadline or "the expiration date". Many of our actions need to be structured in this way, sometimes even very precisely. Still, I stipulate that it is not a typical feature of the plans we make. We can reasonably plan to do or achieve something, without having the deadline specified. Suppose I have a plan to be a lawyer - I cannot, strictly speaking, have a precise deadline for this plan. What if the deadline was set for my 30th birthday and one day after that date I know that my plan is not yet fulfilled completely and that I need one-two more years to become a lawyer? If we agree that plans are partial, we may abandon this problem with no regret ${ }^{29}$.

A further issue, plan completeness, is even more problematic. According to this postulate, plans should be complete in the sense that they should "cover the whole projected action". Yet Kotarbiński notices that it is "apparently in conflict with the necessity of avoiding too detailed planning" [Kotarbiński 1983: 28], but it does not stop him from enlisting completeness to the requirements of a plan... If this manoeuvre were to be taken seriously, one would judge it totally wrong. Plans are (synchronically and diachronically) partial, therefore they are not complete - and they should not be so, otherwise we would always need to overload ourselves with too much information (and accompanying intentions) preventing the completeness of our plan at the time of planning. This is both in contradiction to our mental economy (resource-boundedness) and to the Kotarbińskian idea of practical realism [Kotarbiński 1965: 118]. Kotarbiński appears to detect different descriptive features of plans, which show their importance in some contexts, but he has not detected any norm here.

Let us take stock. When discussing plan detail, long-term planning, plan deadlines and completeness, I have kept on referring to the idea of our mental economy. This idea touches some deeper pragmatic mechanisms of our agential psychology. It is time now to take a closer look at the idea of plan econom $y^{30}$. Kotarbiński says that a plan may be economic in three aspects: 
economy $_{1}$ : a feature of planning itself, understood as plan-making ${ }^{31}$, economy 2 : the use of $\operatorname{plan}^{32}$ : the (easy or difficult) way in which we put a plan into practice,

economy $_{3}$ : the selection of steps and means to the chosen goal; [see Kotarbiński 1965: 118]

Again, if we accept $P T I$, some problems, which result from $P E$ and reism, disappear. Specifically, we can ignore economy ${ }_{2}$, since it implies that plans are, according to externalism, "written down", i.e. function as complete recipes or instructions for actions. Let us consider economy ${ }_{3}$. I understand it as a substantial specification of the demand for meansend coherence: we should adjust the progression from the means to an end in an utilitarian manner, in accordance with the reasons for or against some options. So, economy of planning, in this sense, should be the result of structuring character of prior intentions combined with relevant deliberation. If I plan to go to California from Warsaw, I should take a connecting flight from, say, Munich or Chicago - not from Moscow or Taipei. In this context, Bratman says only that prior intentions are "framework reasons" which structure the process of weighing the reasons [Bratman 1987: 34]. If we combine it with the Kotarbińskian account, plan economy ${ }_{3}$ only applies to plans occasionally because it implies that some options are more reasonable than others, and this can be determined without the plan structures. To sum up, economy is a more general praxiological norm, important for planners, but not essential for planning itself.

Consider now economy. . What does it mean that plan-making is economic? Economy ${ }_{1}$ does not say anything particular about the way in which plan-making should be economic. Recall the principle of economy as ascribed to actions: the fewer mental and physical resources it requires to reach its goal, the more economic an action is. So, here we are looking for the condition which might be expressed as some optimizing principle of our psychology of planning. Let us have a look in PTI. We have seen that the agglomeration of intentions has some distinct optimizing dimension: that building larger compound intentions - instead of having two separate ones - economizes our diachronic actions. Kotarbiński did not elaborate on the idea of economy ${ }_{1}$ when he enumerated three aspects of the economy of plans. Nevertheless, in the Treatise we can find something very interesting in this context. When discussing various types of action economization, Kotarbiński focused inter alia on doing two separate things "at one stroke". He calls this "the 
accumulation of results around a given measure", and defines it as the use of relevant means to reach two goals which it is possible to reach separately by employing two different means [Kotarbiński 1965: 109]. And this is precisely the same idea as the Bratmanian "agglomeration of intentions", but expressed in different language. One should say a bit more about this striking similarity between the theories of Kotarbiński and Bratman ${ }^{33}$, but here it is enough to emphasize that the talk about the economy $y_{1}$ of planning seems reasonable; one needs only to understand it properly. Kotarbiński gave only a clue to such understanding, but his praxiology, supported by the Bratmanian agglomeration principle, allows a fuller elaboration. Plan-making can be economic in the sense that we may agglomerate our intentions into a larger compound intention, which may function in a complex chain of intentions. Naturally, such economic plan-making not only economizes the processes in our agential psychology, but also - economizes our agency. In this sense, in the agglomeration of intentions, an example of economy $y_{1}$ can also turn out to be consistent with economy ${ }_{3}^{34}$.

Let us now consider briefly the next two issues. Kotarbinski states that each of these is a necessary normative condition of a good plan and that each appears as operativeness. According to the Polish praxiologist, plans as expressed sentences should be operative in the sense that they should facilitate and simplify the transition from conceiving their details to their realization. This aspect of operativeness of plans is a problem of the practical application of expressions of plans, so it refers to the same problem as economy 2 (i.e. the use of plans). On the other hand, they should be operative in the sense that the set of intended actions should result in an effective action [Kotarbiński 1961: 198; 1965: 119; 1983: $26,28]$. We can distinguish these two by calling the former external, and the latter - internal or immanent plan operativeness. As economy 2 , the external operativeness of plans does not belong to our area of interests, which is, recall, narrowed down to the sphere of agential psychology $(P T I)$. It belongs to the broad issue of the pragmatic dimension of language $^{35}$. Immanent plan effectiveness, as Kotarbiński noticed, should be a result of meeting all the requirements that effective or efficient plans have to meet. It seems clear that the latter is not a substantial praxiological norm; it depends on the other demands on a plan. What is more - it is typically context-dependent. So, operativeness in both senses does not seem to be interesting in our PTI-oriented approach to the praxiology of planning. 
Before considering the very last norm of planning, we should discuss shortly the question which has been touched on in the two previous paragraphs, namely the problem of the communicativeness of a plan. When planning becomes intersubjective, when several agents want to reach one and the same goal, the plan content must be expressed in an easily understandable language, it must be readable - "not in the linguistic sense, but in the sense that the schedule of the action in question is clearly perceived" [Kotarbiński 1983: 29]. Therefore, the only difference between the external operativeness and economy 2 and the communicativeness of plan is that the latter implies a cooperative action, while the former does not. I agree with Kotarbiński that it is an important aspect of acting together: if I am to cooperate, I should like to know that the other cooperating agents understand what we are to do together. Still, it seems that it is not a problem typical for PTI, namely, for the future-directed intentions which build a plan (even if a plan is realized in shared actions) ${ }^{36}$. This is a problem for PTI only as extended to the theory of collective action: the latter may require other conditions than the former describes.

Finally, let us consider the last - but not the least important - norm of plans: plasticity (or flexibility). According to Kotarbiński,

\footnotetext{
"Every plan deals with future events, therefore at the moment we formulate it we do not know all the circumstances which will accompany them. Hence a plan must leave room for some uncertainty and conjectures concerning the course of events and states of affairs assumed by projected actions. And what if things happen otherwise? In order to cope with such a situation a plan should indicate, or at least admit of, certain modifications of its schedule; it should contain nothing which makes a modification of this sort impossible; nothing should prevent switching from one track to another. The less a plan contains elements which obstruct its possible modification, the more versatile it is." [Kotarbiński 1983: 26]
}

This rings true, but it is rather a metaphor. It states only that plans should be flexible in the sense that a plan should allow for modifications in the means, because of possible changes in the environment of a planner. Discussing plasticity in [1962a] Kotarbiński was more verbose. He said that a plan should be underdetermined with respect to the means which allow me to realize it. Such underdetermination may come in two versions. The first (let us call it soft underdetermination) relies on the "lax alternativity of steps": the means are optional in the alternatives which we accept with respect to two possible planning scenarios that 
may later appear. Turn back to my plan to visit California in April. Suppose, that I have a subplan to meet a friend in Sacramento, but - due to his anticipated move to LA, I am not sure if he will be in Sac or in LA. I need to include two scenarios for my overall plan: the subplan of going to Sacramento and the subplan of going to LA. Softly underdetermined plans require two-tracked planning. The second version (call it hard underdetermination) is different. It leaves the means to the plan end completely open and optional; the means may be employed liberally according to the information about the environment [Kotarbiński 1962a: 195]. The same plan for April: I have a subplan to meet a friend, but (suppose), he is currently on the job market, and I know only that he has four offers from Californian universities (and he has not told me which ones). In April he will move to one of the university cities. So, because of the "amplitude of options", my plan to meet a friend in California should be hard-underdetermined.

It is interesting that plasticity of planning easily fills in the lacuna of the Bratmanian account of PTI. Before I explain this in detail, let me make a few remarks about underdetermination. Firstly, the plan underdetermination to which Kotarbiński refers to piggybacks on the idea of the partial character of plans, but in the case of plasticity, such fragmentariness (both synchronic and diachronic) is deliberate: a planner consciously and liberally uses her knowledge to devise more than one scenario for his overall plan. Secondly, plans are undetermined semantically ${ }^{37}$ : the connections between intentions (as plan states) are underdetermined with respect to the partial character of plans and to the responses of a planner to the possible fluctuations in the environment. In other words, if plans are chains of future-directed intentions, the semantic relations between them cannot stiffen the plans, otherwise our planning would inertially lead to practical errors whenever our plan environment fluctuated. Now, what is the lacuna in PTI I have mentioned?

As we remember, Bratman's discussion of plan stability is narrowed down to the case of "nonreflective (non)reconsideration"; he did not explore the problem of the simple abandonment of intentions in the planning structure. Kotarbińskian plasticity helps explain this problem away - what is more, it does it in a Bratmanian spirit. The idea is that plasticity enters the scene of our actions whenever there is the abandonment of future-directed intentions. More precisely, we may safely abandon our decisions about what to do in the future if we are plastic planners. So, plan plasticity, much alike plan stability, is also a thesis about an important 
aspect of our agential psychology. Elsewhere (Makowski, submitted), I have tried to frame planning plasticity as a meta-stability of intentions, moored in the same stabilizing dimension of our psychology; such dimension works differently in different planning ecosystems. Bratman shows in detail how we retain our stability (as reasonable) in stable practical environments. Kotarbiński's plasticity corrects his account in the sense that it shows, that psychological diachronic stability changes when our environment fluctuates. Consequently, the overall force of the picture of stability Bratman gives has to be critically supplemented by our support of plasticity. Elsewhere (Makowski, submitted), I have tried to construe such a support. I pointed to three issues: (1) plasticity, as a way to retain the meta-stability of our intentions, helps avoid the inertial aspects of our planning and practical errors which may result from it. (2) Plasticity stabilizes our planning when we have to simply abandon some practical scenarios. This results in substitutes and surrogates in our subplans or in the reframing of the whole plan, but it always helps retain some more general practical tendencies we initially had in our planning. (3) Plasticity warns us against taking the idea of resource-limited agency too literally. Bratman took it as an argument for the importance of stability: we are resource-limited creatures, so it pragmatically supports nonreconsideration of prior intentions. Still, agents with limited mental and physical resources may be plastic planners: to have two-tracked planning scenarios or to be ready to modify or adjust a plan when needed - these psychological tendencies require some imagination and knowledge, but are compatible with the account of resource-limited agents. Thus, generally, Kotarbinskian plasticity is sound and may be combined with PTI.

\section{Conclusion: the grammar of planning}

I have tried to arrange here a kind of "conceptual meeting" of the so called planning theory of intention and the praxiological account of plans, and I have given a brief comparative discussion of the two. This proved to be demanding for both. It revealed serious difficulties, especially on the side of praxiology (reism, $P E$, redundant characteristics), but they were not unsolvable. Despite the fact that "the philosophical communication" between PTI and praxiology is hard, its overall outcome appears to be fruitful: after modifications and critical reinterpretations, they mutually support one another. As I suggested at the beginning, they work in the same business. This business can be called (to travesty Kotarbiński) the 
grammar of planning. The main result of the discussion I have proposed is as follows: despite many intra-theoretical problems, praxiology has something important to say about the features and norms of planning. PTI, on the one hand, helps to reframe praxiology, but, on the other hand, it reveals a few deficiencies, which can be easily removed.

To sum up: PTI and praxiology (after some corrections in both cases) agree that plans are complex but typically partial chains of future directed intentions, which are structured hierarchically. Praxiology is also competent to specify the way we should understand the partial character of plans, and, in this sense, it interestingly enriches their descriptive characteristics.

$P T I$ and praxiology differ in their understanding of the demands that planning has to meet. Bratman pointed to four norms, which all govern plan states: means-end coherence, internal and external consistency, reasonable stability and agglomeration. Praxiological perspective, after merging with PTI, could not embrace the idea of reasonable stability, but it added the fifth norm, plasticity. This norm reveals its role only on the level of complex planning in unstable environments. Still, it unveils the aspects of our psychology which are crucial to being effective agents. Praxiological thinking also shows that the principle of agglomeration of intentions is a type of broader praxiological norm, which can be called economization. Even these two ideas show, that there are tangible advantages to the praxiological approach to planning. If my arguments (which have been given largely as a reinterpretation of Kotarbiński), are sound, praxiology should be taken seriously in action theory. There are at least three reasons to take it seriously: firstly, it offers substantial enrichment of the account of planning. Secondly, it shows the reasons for extending the theory of plans in an optimizing direction. Finally, it may also enhance action theory in a broader sense, since it explicitly orients practical philosophizing towards effectiveness and efficiency. In this way, it proves to be still vivid and worthy of detailed examination - especially when one faces the fact that the very anchors of praxiology are in Kotarbiński's writings, which appeared totally outside mainstream action theory in the early 50s and 60s.

We may now turn back to the idea I have been referring to throughout the text - that praxiology remains interestingly close to the conception of resource bounded rationality. True, praxiology does not take this idea at its "face value" (as Bratman's PTI seems to take). It shows critically where being economic really matters: to be still effective, to get things 
done, we sometimes need to engage more resources (more energy, more imagination, more knowledge - and sometimes more money) than initially predicted. But it does not mean that effective agency requires unusual resources: effectiveness and efficiency in actions are normally available for resource-limited creatures like us.

\section{Notes}

1. Work on this paper has been supported by Polish National Science Centre Grant (UMO-2011/03/B/HS4/04162).

2. Es besteht geradezu ein Finalisierungszwang, da ohne vorgängige Zielsetzung kein Sichverhalten oder gar Handeln möglich ist [Krämer 1992: 129].

3. This is a travesty of a text about Misesian "praxeology". See: http://www.praxeology.net/praxeo.htm.

4. Praxiologists (even Kotarbiński himself) used to offer slightly more nuanced definitions. For the purposes of this paper, I propose these simplified accounts. It is only worth noting that the praxiological understanding of efficiency and economy is much more basic than the one used by economists, since it does not imply quantitative measurement.

5. Compare: "By praxiology I mean the science of efficient action. Consequently, the tasks of praxiology are to formulate and to prove recommendations concerning what must be done: what is advisable to do under definite circumstances in order to attain the intended results in the most efficient way. To put it more briefly, the task of praxiology is to investigate the conditions on which maximization of efficiency depends. It is superfluous to add that the formulations given above cover both positive recommendations and warnings and the avoidance and eliminations of effects that disagree with our intentions as well as of all shortcomings of efficiency in action" [Kotarbinski 1962b: 211].

6. One of the important ideas behind Kotarbiński's project was to show why we need explicit and thoroughly elaborated praxiology. I shall not discuss the problems connected with this idea here.

7. In this way praxiology enters the debate on the problem of know-how.

8. For exhaustive presentation of Kotarbińskian reism, see [Smith 2006].

9. At least, the one of Davidsonian proveninence.

10. Technically speaking, a nonfactualist would say that sentences about plans do not assert propositions putatively expressed in these sentences (in other words, plans as symbolic images express no proposition; they are not genuine representations of a putative domain of facts). One could try to save this conception by employing fictionalism and so called "quasi-assertions" in the spirit of Bas van Fraassen's constructivism (see e.g. [Kalderon 2005, Rosen 2005]), but this is a different matter.

11. In Makowski (unpublished), I defend the view that Kotarbińskian approach literally reifies agency and it cannot serve as a feasible ontological basis for action theory. But, at the same time, reism made some interesting shifts in action theorizing to the effect that occasioned praxiology is, to some extent, still terra incognita in the philosophy of action.

12. To remain precise, it would be worth noting that the reistic understanding of plans is holistic in the sense that it tries to capture both the processes of planning, 
the agents involved and the artifacts (used as tools, and produced as effects of planning). Cf. "According to concretism, reality consists exclusively of changing, four-dimensional, that is, spatio-temporal, solids; what temporal plans refer to are objects of this sort and their temporal phases. In particular, objects of this sort can be identified with acting persons, what they produce, substances used, or the wholes consisting of acting persons, their tools and substances they use. Therefore, a temporal plan of an action, for example, a plan of a journey, describes (...) the temporal sequence of shorter actions which are constituents of the complex action we deal with; strictly speaking, such a plan gives a detailed account of a journey: it begins with the phase when a whole which includes passengers, drivers, carriages, undergoes a change (e.g., it moves from $A$ to $B$ ), and is followed by another phase of the same whole, then by still another, and so on" [Kotarbiński 1983: 24].

13. In this part I use characteristics I give in Makowski (submitted).

14. One might object that this is the essence of PTI: "future-directed intentions" and "plans" may be used interchangeably, because both illuminate themselves. But notice, if this is what Bratman would like to say, then the talk of plans as built of intentions is void. It would also bear other serious intra-theoretical problems. In what follows, I shall try to show some advantage in taking the difference in complexity between intentions and plans seriously. In "Intention inertia and the plasticity of planning" (Makowski, submitted) I accept the same strategy to highlight the problems in the Bratmanian construction of the norm of stability.

15. That feature, by Bratman called sometimes "inertia", is, in turn, a result of more general psychological propensities. Bratman treats all these similarly (I show the virtues of accepting more precise distinctions in (Makowski, submitted)).

16. Kotarbiński was perfectly aware that such planning exists. But - no surprise, given his reism - he interpreted it in a completely different way: "Somebody may make fantastic plans concerning his life; he rather lets his thoughts wander capriciously than seriously considers how to live" [Kotarbiński 1983: 22].

17. For a concise presentation of functionalism in philosophy of mind, see e.g. [Levin 2013].

18. How these norms are to be conceived is a complex issue. To simplify, here I accept the uncomplicated talk of normativity in action, which can be defined roughly as something the ignorance of which results in practical errors.

19. Here I summarize Bratman's thoughts which have been repeated in many places; in this summary I ignore a few historical nuances of how this set of norms evolved in his writings [compare, for example: Bratman 1987: 3-32, 2009: 159].

20. See my (Makowski, submitted).

21. Cf. "I will be making the simplifying assumption that an agent abandons a prior intention only as a result of some form of reconsideration of that prior intention. (...) In an earthquake I might just abandon my prior intention to play bridge tonight without engaging in anything that amounts to reconsideration of that intention" [Bratman 1987: 183, n1].

22. In his three essays on temptation [see Bratman 1999b, 1999c, 2007a], Bratman declared that he changed his view about stability for a less „,default"- and more control-oriented rational one. In Makowski (submitted) I claim that his modified view has no impact on the overall picture of stability Bratman offers in his later works.

23. If I intend now to go to California in April and I intend now to have a glass of Californian cabernet sauvignon tonight, these two intentions do not play in the same game and do not have a common practical scenario. 
24. Zhu offers more detailed support for intention agglomeration and defends it with regard to some criticisms. His account, however, focuses on the rationality of agglomerating intentions, and leaves their praxiological dimension without explanation. See [Zhu 2010].

25. Similarily to Bratman's approach to planning norms, this set evolved in Kotarbińskian action theory. Here I offer a synthetic approach mainly on the basis of the 1956 paper, including also some clarifications from [Kotarbiński 1962a, 1965], without going into differences between their expositions.

26. In the Treatise Kotarbinski calls internal consistency the unity or (synchronic) consequence [Kotarbinski 1965: 119], and waives to give even an imprecise definition.

27. By saying this, I do not claim that aesthetics does not matter at all in our actions. In some practical contexts, it may be very important or even crucial. The point is only that it is not important praxiologically, i.e. in terms of general norms.

28. It is absent in [Kotarbiński 1962a and 1983].

29. Note that one might respond that the idea of terminus ad quem can be explained away by saying that it is simply redundant: a plan has its terminus ad quem iff it contains the additional future-directed intention which specifies the deadline of that plan.

30. Also absent in Kotarbiński [1962a and 1983].

31. Precisely, Kotarbiński spoke of plan „formulation“, but this can be reinterpreted - according to the strategy accepted here - in psychological terms.

32. This aspect should not be confused with "the use of plan" in the sense of Martha Pollack: i.e. the functional roles of plans. See [Pollack 1992].

33. This is a further reason to interpret and enrich PTI praxiologically, and the opposite - to reframe praxiology in terms of $P T I$.

34. To reduce two senses of plan economy, one could offer a kind of „Simple View” on the economy of planning, which would state that if $A$ makes a plan economically, $A$ 's actions which result from this plan are economic (at least in some sense). This view is a generalization of the idea that agglomeration of intentions has agglomerating effects in actions. This generalization is only a hypothesis. Although its consequences are interesting and far-reaching, I leave it here unexamined.

35. There already exists a specific field in praxiology, which investigates the grounds of such problems. It is called the theory of optimal sign or praxiosemiotics and has been proposed by Tadeusz Wójcik.

36. It seems that agents involved in effective cooperation do not need to have the same plan (in terms of sharing future-directed intentions which build that plan) to act in accordance with that plan: cooperation does not require shared intentions and their semantics. I leave this problem for another study.

37. I understand semantic underdetermination broadly in Recanati's sense, as a dependence on pragmatic factors [Recanati 2002]. The view that plans are underdetermined this way I proposed in (Makowski, submitted).

\section{References}

Alexandre, V., Gasparski, W., 1999, The Roots of Praxiology. French Action Theory from Bourdeau and Espinas to Present Days, (Praxiology: The International Annual of Practical Philosophy and Methodology, Volume 7) Victor Alexandre \& Wojciech W. Gasparski (eds), Transaction Publishers 1999. 
Bratman, M. E., 1987, Intention, Plans, and Practical Reason, Cambridge, MA: Harvard University Press.

Bratman, M. E., 1983, 'Taking plans seriously', Theory and Social Practice, 9(2-3): 272-287.

Bratman, M. E., 1992a, 'What is intention?' In Intentions in Communication, Philip R. Cohen, Jerry Morgan, Martha E. Pollack (eds.), Cambridge, MA - London: MIT: 76-103.

Bratman, M. E., 1992b, 'Planning and the stability of intention', Mind and Machines, 2: $1-16$.

Bratman, M. E., 1999a, 'Introduction: planning agents in a social world', in Michael E. Bratman, Faces of Intention. Selected Essays on Intention and Agency, Cambridge, Cambridge UP: $1-15$.

Bratman, M. E., 1999b, 'Planning and temptation', in M. E. Bratman, Faces of Intention. Selected Essays on Intention and Agency (pp. 36-57). Cambridge, Cambridge UP.

Bratman, M. E., 1999c, 'Toxin, temptation, and the stability of intention', in M. E. Bratman, Faces of Intention. Selected Essays on Intention and Agency (pp. 58-90). Cambridge: Cambridge UP.

Bratman, M. E., 2007a, 'Temptation revisited', in M. E. Bratman, Structures of Agency (pp. 257-282). Oxford - New York: Oxford UP.

Bratman, M. E., 2007, Structures of Agency. Oxford - New York: Oxford UP.

Bratman, M. E., 2009, 'Modest sociality and the distinctiveness of intention', Philosophical Studies, 144: 149-165.

Bratman, M. E., 2010, 'Agency, time, and sociality,' Proceedings and Addresses of the American Philosophical Association, 84(2): 7-26.

Bratman, M. E., 2013, 'The fecundity of planning agency', in Oxford Studies in Agency and Responsibility, David Shoemaker (ed.), Oxford, Oxford UP: 47-69.

Holton, R., 2004, 'Rational resolve,' Philosophical Review 113: 507-35.

Kalderon, M. E., 2005, 'Introduction' in Fictionalism in Metaphysics, Mark Eli Kalderon (ed.), Oxford; Oxford UP, 1-13.

Kolodny, N., 2008, 'The myth of practical consistency,' European Journal of Philosophy, 16: 366-402.

Kotarbiński, T., 1962a, (original Polish version in 1961), 'The property of a good plan', Estratto Rivista Methodos, Milan, 13(51/52): 189-201.

Kotarbiński, T., 1962b, 'Praxiological sentences and how they are proved', in Logic, Methodology, and Philosophy of Science, Ernest Nagel, Patrick Suppes \& Alfred Tarski (eds.), Stanford, Stanford University Press.

Kotarbiński, T., 1965, (originally in 1955), Praxiology: An Introduction to the Sciences of Efficient Action. Transl. by Olgierd Wojtasiewicz, Oxford, Pergamon Press/ Warszawa PWN.

Kotarbinski, T., 1983, (originally in 1956), 'The general concept of plan', Dialectics and Humanism, 10(4): 15-31.

Kotarbinski, T., 1964, 'Practical error', Danish Yearbook of Philosophy, Copenhagen 1: $65-71$.

Krämer, H. J., 1992, Integrative Ethik, Frankfurt am Main, Suhrkamp.

Levin, J., 2013, “Functionalism”, The Stanford Encyclopedia of Philosophy (Fall 2013 Edition), Edward N. Zalta (ed.), URL $=<$ http://plato.stanford.edu/archives/fall2013/ entries/functionalism/>.

Makowski, P., submitted, 'Intention inertia and the plasticity of planning.

Makowski, P., unpublished, 'Does praxiology rest on a mistake?'.

Pollack, M. E., 1992, 'The uses of plans', Artificial Intelligence, 57(1), 43-68. 
Recanati, F., 2002, 'Does linguistic communication rest on inference?', Mind \& Language, 17, 105-27.

Rosen, G., 2005, 'Problems in the history of fictionalism', in Fictionalism in Metaphysics, Mark Eli Kalderon (ed.), Oxford; Oxford UP, 14-65.

Smith, B., 2006, 'On the phases of reism', in Actions, Products, and Things. Brentano and the Polish Philosophy, Arkadiusz Chrudzimski \& Dariusz Łukasiewicz (eds.), Frankfurt: Ontos Verlag, 115-176. 